\title{
A Cross Sectional Study of the Impact of Human Immunodeficiency Virus, Hepatitis B Virus and Hepatitis C Virus on Rheumatoid Factor Production
}

\author{
Etienne Atabonkeng PHILÉMON ${ }^{1} \mathbb{D}$, Christopher TUME ${ }^{1}$ (D) Marie Claire OKOMO ASSOUMOU ${ }^{2}(\mathbb{D}$, \\ Salomon TCHUANDOM BONSI ${ }^{1}$, Ikomey Mondide GEORGES ${ }^{2}$, , Hervé OUAMBO FOTSO $^{3}$ (D), \\ Lyonga EMILYA ${ }^{2}$, Mesembe Tonga MARTHA ${ }^{2}$, , Madelaine NGANDEU-SINGWE2(1) \\ ${ }^{1}$ Department of Biochemistry, University of Dschang, Dschang, Cameroon \\ ${ }^{2}$ University of Yaounde I, Faculty of Medicine and Biomedical Sciences, Yaounde, Cameroon \\ ${ }^{3}$ University of Buea, Faculty of Health Sciences, Buea, Cameroon
}

\begin{abstract}
Objectives: This study aims to investigate how human immunodeficiency virus (HIV), hepatitis B virus (HBV) and hepatitis C virus (HCV) affect the production of immunoglobulin $\mathrm{M}$ (IgM)-rheumatoid factor (RF).

Patients and methods: The study included 405 voluntary participants (139 males, 266 females; mean age $39.4 \pm 17.9$ years; range 3 to 88 years) randomly recruited by a consecutive sampling technique in the main health facilities of the Center, East, Far North, Littoral and West regions of Cameroon. We excluded persons under treatment or hospitalized for any form of primary autoimmune disease. Blood samples were collected and used for serological analyses. We sought for the HIV antibodies (Ab); the core antibody (HBcAb), the surface antigen (HBsAg), and the replicative antigen (HBeAg) of the HBV; HCVAb of HCV and the IgM-RF.

Results: The prevalence of HIVAb was $7.61 \%, 38.7 \%$ for $\mathrm{HBCAb}, 5.43 \%$ for $\mathrm{HBsAg}, 1.26 \%$ for $\mathrm{HBeAg}$ and $6.41 \%$ for IgM-RF in the study population. The Far North region had the highest prevalence of IgM-RF $(9.8 \%)$ and the Littoral region had the lowest prevalence (3.2\%). The prevalence of RF was $6.7 \%$ and $5.7 \%$ for females and males, respectively (sex ratio of 2.25 ). The IgM-RF prevalence was $9.7 \%, 8.9 \%, 9.1 \%$, and $27.8 \%$ in participants with positive serological results for HIVAb, HBCAb, HBsAg, and HCV, respectively.

Conclusion: Infection by HIV and HBV showed to poorly stimulated IgM-RF production. However, IgM-RF was highly produced in HCV infected participants. Increased IgM-RF production may contribute to cytotoxicity in tissues or organs of HCV-infected patients, leading to the onset of autoimmune diseases.

Keywords: Human immunodeficiency virus; prevalence; rheumatoid factor; viral hepatitis.
\end{abstract}

Rheumatoid factors (RFs) are autoantibodies against the fragment crystallizable region of immunoglobulin $\mathrm{G}$ (IgG) and found in $70 \%$ to $80 \%$ of rheumatoid arthritis (RA) patients being associated with more aggressive joint disease and increased frequency of extraarticular manifestations. Humoral immunity participates in pathogenic mechanisms through formation of immune complexes. ${ }^{1}$ Although the action mechanism of RF leading to autoimmune disease (AID) is still poorly understood, it is known that the reaction of IgM-RF class with IgG results in immune complexes which could be deposited in the synovial membrane, on blood

Received: May 24, 2016 Accepted: September 20, 2016 Published online: July 31, 2018

Correspondence: Tume Christopher, MD. Department of Biochemistry, University of Dschang, P.O. Box 67, Dschang, Cameroon.

Tel:0023775407838 e-mail: tumechrist@yahoo.fr 
vessels or many other locations in the body leading to activation of complement proteins and the destructive action of cytotoxic cells. ${ }^{1}$ High titers of IgM-RF in the serum of a RA patient should be considered as an important predictor of outcome of osteocartilaginous damage. ${ }^{2}$ AID may evolve chronically, leading to destruction of target tissues and sometimes loss of its function. ${ }^{3}$

The world at large and Africa in particular are facing several endemic viral diseases that include human immunodeficiency virus (HIV), hepatitis $B$ virus (HBV) and hepatitis $C$ virus (HCV) infections, but little is known about the influence of these diseases on the production of autoantibodies in the African population. However, studies carried out on Caucasians have attempted to establish correlations between some viruses and stimulation of the immune system. ${ }^{4}$ Viral infections are particularly highly prevalent in Africa where $\mathrm{HIV}$ is responsible for millions of deaths ${ }^{5}$ while the prevalence of infection with other viruses such as hepatitis B and $C$ remain high and keeps increasing in some countries. However, information is limited on the relationship between these viral infections and autoantibody production. Therefore, in this study, we aimed to investigate how HIV, HBV and HCV affect the production of IgM-RF.

\section{PATIENTS AND METHODS}

This study was conducted at Faculty of Medicine and Biomedical Sciences, University of Yaounde I. between $05^{\text {th }}$ February 2014 and $10^{\text {th }}$ October 2014. The study included 405 voluntary participants (139 males, 266 females; mean age $39.4 \pm 17.9$ years; range 3 to 88 years) randomly recruited by a consecutive sampling technique in the main health facilities of the Center, East, Far North, Littoral and West regions of Cameroon. The sample size was computed based on a prevalence of $50 \%$ since no known prevalence of IgM-RF amongst infected patients was available. In each of the selected regions, the most popular and most visited sites with ethnic diversity of population were selected by a convenience sampling technique. The study participants were recruited in health facilities inside the chosen sites and were either persons coming for consultation or healthy persons accompanying patients. We excluded patients under hospitalization and those who were presenting evidence of primary autoimmune diseases. Participants aged three (03) years and over, who freely accepted to participate or whose parents or guardians consented on their behalf were included in the study. For participants below 15 years of age ( $<15$ years), a parental agreement was needed. After careful explanation of the study protocol and objectives, a data collection sheet was used to collect sociodemographic information including the sex, age and region of origin of each participant. Thereafter, $5 \mathrm{~mL}$ of whole blood was collected from each participant in a dry tube and further centrifuged (3000 g, 10 minutes) after two hours to obtain serum which was used for serological analyses. The protocol used in this study was approved by the Cameroon National Ethics Committee for Human Health Research (Decision N²016/04/757/CE/CNERSH/SP of 28 April 2016). A written informed consent was obtained from each participant. The study was conducted in accordance with the principles of the Declaration of Helsinki.

All serum samples underwent the following tests: HIV screening test using the Determine HIV $1 / 2$ kit (Abbott, Tokyo, Japan) and further with ImmunoComb BiSpot II HIV 1/2 kit (Orgenics Ltd., Yavne, Israel); screening for the core antigen of $\mathrm{HBV}$ (IgM-HBc) using the $\mathrm{HBcAb}$ IgM kit (Diagnostic Automation/Cortez Diagnostics, Inc., California, USA), the surface antigens of $\mathrm{HBV}$ (HBsAg) using the (Hepatitis $\mathrm{B}$ virus Test Strip, (Abbott, Montreal, Canada), the replicative antigen of $\mathrm{HBV}(\mathrm{HBeAg})$ using the $\mathrm{HBeAg}$ test cassette from Diagnos, and Hepatitis $\mathrm{C}$ antibodies (HCVAb) using the DiaSpot HCV kit (Abbott, Montreal, Canada). Finally, the INMESCO-RF kit (INMESCO GmbH, Neustadt (Wied), Germany) was used to detect the IgM-RF; a positive result for the IgM-RF test was characterized by a visible agglutination on the test plate two minutes following homogenization by rotating the plate on a mechanical homogenizer. Positive and negative controls were used to validate our results.

\section{Statistical analysis}

Our data were documented and frequencies were calculated using the Statistical Package 


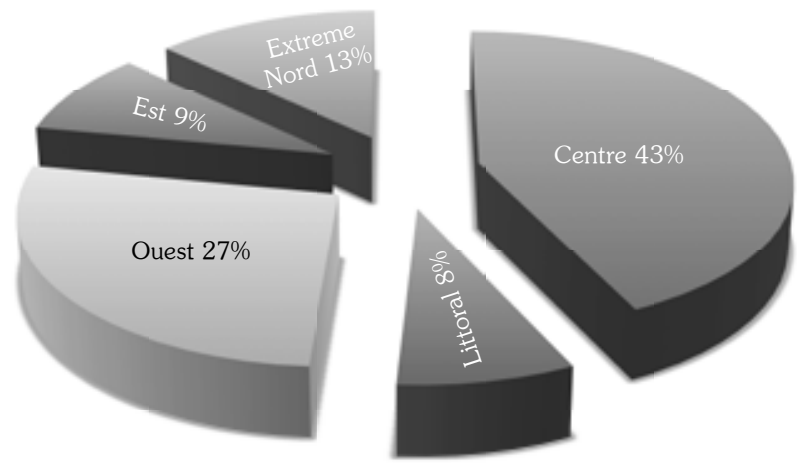

Figure 1. Representation of participants in study areas. Center region was most represented followed by West region. Fewer participants were obtained in Littoral region.

for the Social Sciences version 15.0 software. The correlations between parameters were evaluated by calculating the $\mathrm{p}$ value using the Fischer exact test and a $p$ value less than 5\% $(p<0.05)$ was considered to be statistically significant.

\section{RESULTS}

The participants were unequally distributed with the highest proportion of $43 \%$ (176 participants) originating from the Centre and the lowest proportion of 9\% (38 participants) originating from the East region (Figure 1). The study population was divided into nine age groups as shown in Table 1 and the most represented group was that of participants aged 40 to 49 years (21.2\%).

The prevalence of the various parameters measured was as follows: anti-HIV antibodies 7.61\%, anti-HBcAb 38.7\%, HBsAg, 5.43\%, and $\mathrm{HBeAg} 1.26 \%$ (Table 2). The prevalence of IgM-RF was $6.41 \%$ (Table 3). The Far North region had the highest prevalence of IgM-RF (9.8\%) while the Littoral region had the lowest (3.2\%). The prevalence of IgM-RF was $6.7 \%$ and $5.7 \%$, respectively, for females and males, and corresponded to a sex ratio of $2.25(18 / 8)$

Table 1. Distribution of study population as function of age groups

\begin{tabular}{|c|c|c|c|c|c|c|c|c|c|c|c|c|c|c|c|c|c|c|}
\hline \multirow{2}{*}{$\begin{array}{l}\text { Age (year) } \\
\text { Proportion }\end{array}$} & \multicolumn{2}{|c|}{$<15$} & \multicolumn{2}{|c|}{$15-19$} & \multicolumn{2}{|c|}{$20-29$} & \multicolumn{2}{|c|}{$30-39$} & \multicolumn{2}{|c|}{$40-49$} & \multicolumn{2}{|c|}{$50-59$} & \multicolumn{2}{|c|}{$60-69$} & \multicolumn{2}{|c|}{$70-79$} & \multicolumn{2}{|c|}{$80-88$} \\
\hline & $\mathrm{n}$ & $\%$ & $\mathrm{n}$ & $\%$ & $\mathrm{n}$ & $\%$ & $\mathrm{n}$ & $\%$ & $\mathrm{n}$ & $\%$ & $\mathrm{n}$ & $\%$ & $\mathrm{n}$ & $\%$ & $\mathrm{n}$ & $\%$ & $\mathrm{n}$ & $\%$ \\
\hline Number & 36 & 8.9 & 17 & 4.2 & 78 & 19.26 & 68 & 16.8 & 86 & 21.2 & 62 & 15.3 & 35 & 7.4 & 18 & 4.4 & 5 & 1.2 \\
\hline
\end{tabular}

Table 2. Serological markers tested and positive participants (\%) according to viruses understudy

\begin{tabular}{|c|c|c|c|c|c|c|c|c|c|c|}
\hline \multirow{3}{*}{$\begin{array}{l}\text { Infection } \\
\text { Serological test }\end{array}$} & \multirow{2}{*}{\multicolumn{2}{|c|}{$\frac{\text { HIV }}{\mathrm{HIVAb}}$}} & \multicolumn{6}{|c|}{$\mathrm{HBV}$} & \multirow{2}{*}{\multicolumn{2}{|c|}{$\frac{\mathrm{HCV}}{\mathrm{HCVAb}}$}} \\
\hline & & & \multicolumn{2}{|c|}{$\mathrm{HBcAb}$} & \multicolumn{2}{|c|}{$\mathrm{HBsAg}$} & \multicolumn{2}{|c|}{$\mathrm{HBeAg}$} & & \\
\hline & $\mathrm{n}$ & $\%$ & $\mathrm{n}$ & $\%$ & $\mathrm{n}$ & $\%$ & $\mathrm{n}$ & $\%$ & $\mathrm{n}$ & $\%$ \\
\hline Total participant & 405 & & 405 & & 405 & & 158 & & 405 & \\
\hline Positive & 31 & 7.65 & 158 & 38.7 & 22 & 5.43 & 2 & 1.23 & 18 & 4.4 \\
\hline
\end{tabular}

HIV: Human immunodeficiency virus; HBV: Hepatitis B virus; HCV: Hepatitis C virus; Ab: Antibodies; HIVAb: Human Immunodeficiency Virus Antibodies; $\mathrm{HBcAb}$ : Hepatitis B virus Core Antibodies; HBsAg: Hepatitis B surface Antigenes; HBeAg: Hepatitis B e antigen; HCVAb: Hepatitis C Virus Antibodies.

Table 3. Percentage of participants having positive immunoglobulin M-rheumatoid factor as function of age groups

\begin{tabular}{|c|c|c|c|c|c|c|c|c|c|c|c|c|c|c|c|c|c|c|}
\hline \multirow[t]{2}{*}{ Age groups } & \multicolumn{2}{|c|}{$<15$} & \multicolumn{2}{|c|}{$15-19$} & \multicolumn{2}{|c|}{$20-29$} & \multicolumn{2}{|c|}{$30-39$} & \multicolumn{2}{|c|}{$40-49$} & \multicolumn{2}{|c|}{$50-59$} & \multicolumn{2}{|c|}{$60-69$} & \multicolumn{2}{|c|}{$70-79$} & \multicolumn{2}{|c|}{$80-88$} \\
\hline & $\mathrm{n}$ & $\%$ & $\mathrm{n}$ & $\%$ & $\mathrm{n}$ & $\%$ & $\mathrm{n}$ & $\%$ & $\mathrm{n}$ & $\%$ & $\mathrm{n}$ & $\%$ & $\mathrm{n}$ & $\%$ & $\mathrm{n}$ & $\%$ & $\mathrm{n}$ & $\%$ \\
\hline Participants & 36 & & 17 & & 78 & & 68 & & 86 & & 62 & & 35 & & 18 & & 5 & \\
\hline IgM-RF+ & 6 & 16.7 & 2 & 11.8 & 2 & 2.6 & 5 & 4.65 & 4 & 4.65 & 5 & 8.06 & 2 & 5.71 & 0 & 0 & 0 & 0 \\
\hline
\end{tabular}


Table 4. Prevalence of positive immunoglobulin M-rheumatoid factor as function of biological marker understudy

\begin{tabular}{|c|c|c|c|c|c|c|c|c|c|c|}
\hline & \multicolumn{2}{|c|}{ HIVAb } & \multicolumn{2}{|c|}{$\mathrm{HBcAb}$} & \multicolumn{2}{|c|}{$\mathrm{HBsAg}$} & \multicolumn{2}{|c|}{$\mathrm{HBeAg}$} & \multicolumn{2}{|c|}{$\mathrm{HCVAb}$} \\
\hline & $\mathrm{n}$ & $\%$ & $\mathrm{n}$ & $\%$ & $\mathrm{n}$ & $\%$ & $\mathrm{n}$ & $\%$ & $\mathrm{n}$ & $\%$ \\
\hline $\begin{array}{l}\text { Total } \\
\text { participant }\end{array}$ & 405 & & 405 & & 405 & & 158 & & 405 & \\
\hline Positive & 31 & 7.65 & 158 & 38.7 & 22 & 5.43 & 2 & 1.23 & 18 & 4.4 \\
\hline IgM-RF+ & 3 & & 14 & & 2 & & 2 & & 5 & \\
\hline $\begin{array}{l}\text { Prevalence } \\
\text { IgM-RF }\end{array}$ & & 9.67 & & 8.87 & & 9.09 & & 100 & & 27.7 \\
\hline
\end{tabular}

for females. The IgM-RF prevalence was 9.7\%, $8.9 \%, 9.1 \%$, and $27.8 \%$ in participants with positive serological results for $\mathrm{HIV}, \mathrm{HBcAb}$, $\mathrm{HBsAg}$, and $\mathrm{HCV}$, respectively.

The IgM-RF prevalence was $4.8 \%$ amongst participants not infected with any of the three viruses investigated. Also, for all the infected participants, the IgM-RF prevalence was $14.08 \%$. Of the 31 participants infected by HIV, 9.67\% were positive for IgM-RF while $8.87 \%$ of $\mathrm{HBcAb}+$ participants were positive for IgM-RF, with an insignificant correlation between IgM-RF and $\mathrm{HBcAb}(\mathrm{p}=0.1446)$. Also, $9.09 \%$ of $\mathrm{HBsAg}+$ participants were positive for IgM-RF but the correlation between these two groups was again not significant $(p=0.64)$. Then, $27.7 \%$ of the $\mathrm{HCVAb}+$ participants were positive for IgM-RF, with a significant IgM-RF correlation between $\mathrm{HCV}$ seropositive $(\mathrm{HCVAb}+)$ and seronegative (HCVAb-) participants (Table 4).

\section{DISCUSSION}

In our study, we obtained an IgM-RF prevalence of $6.41 \%$ with a higher occurrence in females (sex ratio $=2.25$ ) similar to a prevalence of $7 \%$ with a sex ratio of 2.61 times higher in females obtained in Ivory Coast in a study carried out on 300 participants randomly recruited and aged 3-67 years. ${ }^{6}$ A previous study carried out in five regions of Cameroon revealed that $5.4 \%$ of the population was positive for $\mathrm{RF}^{7}$ while this latter study did not involve subjects aged less than 15 years. Viatte et al. ${ }^{6}$ revealed that $16 \%$ of the healthy population was positive for RF. The $16 \%$ prevalence can be easily understood since the authors used the enzyme-linked immunosorbent assay technique, which is more sensitive and able to detect several isotypes of RF (IgA, IgM, IgG) as compared to the less sensitive agglutination technique used in the previous studies.

Results from this study showed that IgM-RF is more prevalent in females than males. Of the 26 participants positive for IgM-RF, 18 were females and only eight were males, though the difference between the two sexes was not statistically significant $(p=0.83)$. However, some studies demonstrated that autoimmune processes are influenced by sex hormones and that some female hormones have a role in the onset and worsening of disease as evidenced by the higher risk induced by oral contraceptive pills, pregnancy and postpartum. ${ }^{8}$

Also, this study showed that participants below 15 years of age had the highest prevalence of IgM-RF, and this may be due to non-specific activation of the immune system by various infectious and parasitic diseases being more frequent amongst this group of participants. ${ }^{4}$ This high prevalence may also be attributed to occurrence of autoimmune diseases such as juvenile arthritis in some children. ${ }^{9}$ IgM-RF was detected in groups of participants aged lower than 69 years with slight differences, but not in subjects aged over 69 years. This implies that production of IgM-RF occurs early in human life, followed by an arrest. It has been reported that several autoimmune diseases including RA can occur at any age but more clinically between 40 and 60 years. ${ }^{10}$ However, the study of AID prevalence in patients over 65 years remains controversial and suggests that the clinical significance of autoantibodies in the elderly is associated more with health status than the aging 
phenomenon. ${ }^{11}$ An investigation in the Japanese population revealed a positive and significant correlation between age and high levels of RF. Hayahara et al. ${ }^{12}$ also showed that RF increases with age and reported that $20 \%$ of subjects aged over 65 years have a high rate of RF though our study revealed no clear correlation between age and RF detection. Indeed, previous observations contrasted with the results of Gaston ${ }^{13}$ who showed that the prevalence of RF appears to be similar between 20 and 100 years. It should be noted that aging is accompanied by a decrease in immunity, impaired cooperation between $\mathrm{T}$ and $\mathrm{B}$ cells, a decrease in B cell turnover, an alteration in the co-stimulatory pathways, ${ }^{14}$ and this set of phenomena accompanying aging may explain the lack of RF beyond 69 years as observed in our study although the sample size for this age group was small.

The prevalence of IgM-RF amongst HIV participants was $9.70 \%$ although there was no significant association between HIV infection and presence of RF $(p=0.4371)$. This prevalence of IgM-RF was slightly higher compared to its prevalence in non-infected participants, thus suggesting that the virus may by some mechanism be stimulating the immune system and inducing the production of autoantibodies such as IgM-RF. It has been shown that, by their tropism for mucous membranes, viruses can deregulate the physiology of epithelial cells causing modifications on the cell membrane and making them targets of immune reactions. These modified epithelial cells can be stimulated by viral infections but also by immune complexes via activation of toll-like receptors. ${ }^{15,16}$

In our study, the IgM-RF prevalence was generally low amongst HBV-infected and HBV-free participants. The RF prevalence was $100 \%$ for the two $\mathrm{HBeAg}+$ participants although the sample size was small. There was no significant difference for IgM-RF production between HBV positive or negative subjects $(p=0.31)$. This suggested that chronic infection with HBV does not have a strong immunogenic power. However, overall, the prevalence of IgM$\mathrm{RF}$ is higher in HBV patients than in healthy individuals free of HBV infection. Extrahepatic manifestations, including arthralgia and cutaneous manifestations, glomerulonephritis, polyarteritis nodosa and essential mixed cryoglobulinemia, ${ }^{17}$ are also associated with chronic HBV infection. ${ }^{18}$ Chronic HBV infection might also lead to immune diseases including the development of nephrotic syndrome particularly in children. ${ }^{18}$

Our results showed that the prevalence of IgM-RF was significantly higher amongst $\mathrm{HCV}$ infected participants (HCVAb+) compared to those who were HCV-free. Similarly, the association between $\mathrm{RF}$ and $\mathrm{HCV}$ gave a $p$ value of 0.0008 , suggesting a strong correlation between the presence of $\mathrm{HCV}$ and synthesis of RF. This further suggests the existence of a strong immune activity related to the production of RF in the presence of $\mathrm{HCV}$. Mounach et al. ${ }^{19}$ showed that rheumatological manifestations occurred during the infection of $\mathrm{HCV}$, and revealed that the prevalence of RF may be up to $71 \%$ among HCV-infected patients. This high RF production has been shown to be associated with the activity of HCV-related cryoglobulinemia. Mechanisms allowing the virus to stimulate the immune system have been discussed previously. Moreover, Boussema and Rokbani ${ }^{20}$ showed that $\mathrm{HCV}$ infection is associated to extrahepatic manifestations particularly through production of autoantibodies (antinuclear, anticardiolipin antibodies, RF, cryoglobulins). In patients with chronic HCV infection, cryoglobulinemia can be detected in $21 \%-54 \%$ of cases, ${ }^{21,22}$ while unusually high titers of RF are observed in 70\% of cases. ${ }^{21}$

Our study has some limitations. We observed that the human immunodeficiency virus and the hepatitis $\mathrm{B}$ virus have weakly stimulated the production of rheumatoid factor compared to hepatitis C virus; However, our study suffered from a low number of positive patients with different markers studied.

In conclusion, the main objective of this study was to investigate the impact of HIV, $\mathrm{HBV}$ and $\mathrm{HCV}$ on IgM-RF production. Our findings show that the prevalence of IgM-RF is $6.41 \%$ in the study population with a sex ratio of 2.25 in favor of females. Infections by HIV or HBV did not have any significant influence on the production of IgM-RF. However, infection by $\mathrm{HCV}$ strongly induced the production of IgM-RF in the study subjects. It is therefore important to take into consideration the possible occurrence of autoimmune diseases amongst persons infected by $\mathrm{HCV}$. 


\section{Declaration of conflicting interests}

The authors declared no conflicts of interest with respect to the authorship and/or publication of this article.

\section{Funding}

The authors received no financial support for the research and/or authorship of this article.

\section{REFERENCES}

1. Mannik M, Nardella FA, Sasso EH. Rheumatoid factors in immune complexes of patients with rheumatoid arthritis. Springer Semin Immunopathol 1988;10:215-30.

2. Preud'homme JL, Clot $\mathrm{J}$, Pasquali $\mathrm{Jl}$, Youinou P, Saraux A, LeGoff $P$, et al. Autoimmunité et Autoanticorps. Cahier de Formation. Autoimmunité. 1999;13:1-24.

3. Janeway CA, Travers P, Walport M, Shlomchik MJ. Immunobiologie. 6th ed. New York: Garland Science; 2009.

4. Morel J, Combe B. How to predict prognosis in early rheumatoid arthritis. Best Pract Res Clin Rheumatol 2005; 19:137-46.

5. Comparing adult antenatal-clinic based HIV prevalence with prevalence from national population based surveys in Sub-Saharan Africa. Available from: http://data.unaids.org/pub/presentation/2007/ survey_anc_2007_en.pdf UNAIDS; 2007.

6. Viatte S, Flynn E, Lunt M, Barnes J, Singwe-Ngandeu $\mathrm{M}$, Bas S, et al. Investigation of Caucasian rheumatoid arthritis susceptibility loci in African patients with the same disease. Arthritis Res Ther 2012;14:R239.

7. Atabonkeng EP Adiogo D, Emmanuel EM, Herve OF, Owono AM, Okomo Assoumou MC. Evaluation of the prevalence of rheumatoid factor in five regions of Cameroon. Arch Rheumatol 2013;30:226-30.

8. Devouassoux G. Physiopathologie des Hypersensibilités de type III-Immunologie et Mécanismes Immunopathologiques. CHLS et INSERM. 2010;23:3-5.

9. Armengaud JB, Deslandre C. Les arthrites juvéniles idiopathiques: formes oligoarticulaires, Diagnostic et modalités évolutives. Mt pédiatrie 2006;9:3-9.

10. Sany J. La polyarthrite rhumatoïde de l'adulte:
Conception actuelle. Montrouge: John LibbeyEurotext; 2003.

11. Önen F, Türkay C, Meydan A, Dökmetaş HS, Sümer $\mathrm{H}$, Hocaoğlu L, et al. Prevalence of rheumatoid factor (RF) and anti-native-DNA antibodies (anti-nDNA) in different age subpopulations. Turk $\mathrm{J}$ Med Sci 1998;28:85-8.

12. Hayahara C, Ikeda K, Sakanishi Y, Ota T. Incidence of serum rheumatoid factors in elder non-rheumatic individuals. Rinsho Byori 2010;58:211-5. [Abstract]

13. Gaston JSH. Rheumatic diseases - immunological mechanisms and prospects for new therapies. J Clin Immunol 1999;162:704-10.

14. Menzel EJ, Zlabinger GJ, Dunky A, Steffen C. Autoimmunity and T-cell subpopulations in old age. Arch Gerontol Geriatr 1988;7:249-60.

15. Båve U, Nordmark G, Lövgren T, Rönnelid J, Cajander S, Eloranta ML, et al. Activation of the type I interferon system in primary Sjögren's syndrome: a possible etiopathogenic mechanism. Arthritis Rheum 2005;52:1185-95.

16. Gottenberg JE, Cagnard N, Lucchesi C, Letourneur F, Mistou S, Lazure T, et al. Activation of IFN pathways and plasmacytoid dendritic cell recruitment in target organs of primary Sjögren's syndrome. Proc Natl Acad Sci U S A 2006;103:2770-5.

17. Rizzetto M, Canese MG, Aricò S, Crivelli O, Trepo C, Bonino $\mathrm{F}$, et al. Immunofluorescence detection of new antigen-antibody system (delta/anti-delta) associated to hepatitis $\mathrm{B}$ virus in liver and in serum of $\mathrm{HBsAg}$ carriers. Gut 1977;18:997-1003.

18. Willson RA. Extrahepatic manifestations of chronic viral hepatitis. Am J Gastroenterol 1997;92:3-17.

19. Mounach A, Ouzzif Z, Wariaghli G, Achemlal L, Benbaghdadi I, Aouragh A, et al. Primary biliary cirrhosis and osteoporosis: a case-control study. J Bone Miner Metab 2008;26:379-84.

20. Boussema F, Rokbani L. Manisfestation systemique des infections par le virus de l'hepatite C 2006. Available from: http://www.stmi.org.tn.

21. Arauz-Ruiz P, Norder H, Visoná KA, Magnius LO. Genotype $F$ prevails in HBV infected patients of hispanic origin in Central America and may carry the precore stop mutant. J Med Virol 1997;51:305-12.

22. Sitterlin $\mathrm{D}$, Tiollais $\mathrm{P}$, Transy $\mathrm{C}$. Le rôle de la protéine virale $\mathrm{X}$ dans le cycle infectieux des hépadnavirus de mammifères. Virologie 2000;4:217-27. 